\title{
Urea and oxalate inhibition of the serum lactate dehydrogenase
}

\author{
PAULINE M. EMERSON AND J. H. WILKINSON
}

From the Department of Chemical Pathology, Westminster Medical School (University of London), London

SYNOPSIS The serum lactate dehydrogenase ( $\mathrm{LDH})$ of 16 normal subjects was inhibited by 55 to $68 \%$ by the incorporation into the reaction mixture of $0.2 \mathrm{mM}$-oxalate. Oxalate inhibited the serum LDH of 17 out of 19 patients with myocardial infarction to a greater extent, and that of 16 out of 18 patients with liver disease to a lesser extent than that of the controls. The serum LDH of all 16 patients with liver disease was inhibited by $2 \mathrm{M}$-urea to a greater degree and that of eight out of nine patients with myocardial infarction to a lesser extent than that of the normal controls (45-62\%). The serum LDH of five patients with megaloblastic anaemia was also less sensitive to inhibition by urea than was that of the controls. The inhibitory effect of oxalate was greatest with those sera containing an excess of the electrophoretically fast LDH isoenzymes, while that of urea was most marked with those sera in which the slow LDH isoenzymes preponderated. The results of inhibition studies with urea or oxalate correlated well with other indices of isoenzyme composition.

The use of oxalate or urea is recommended as an aid in the enzymatic diagnosis of heart and liver disease, especially when the results of other enzyme tests are equivocal.

The discovery that the lactate dehydrogenase (LDH) of serum and of most tissue extracts consists of five electrophoretically distinct isoenzymes (Vesell and Bearn 1957; Wieland and Pfleiderer, 1957; Sayre and Hill, 1957) has led to important improvements in the diagnostic value of estimation of this enzyme. The isoenzyme patterns observed have a considerable measure of tissue specificity (Nisselbaum and Bodansky, 1959; Plagemann, Gregory, and Wróblewski, 1960), but as the individual isoenzymes have been shown to differ from each other in some of their chemical and catalytic properties, several methods have been suggested for assessing the isoenzyme composition of a raised serum LDH without recourse to electrophoresis. Of these, determinations of the serum $a$-hydroxybutyrate dehydrogenase (HBD) (Rosalki and Wilkinson, 1960; Elliott and Wilkinson 1961) and the heatstable lactate dehydrogenase (Plagemann et al., 1961) have found applications in confirming the diagnosis of suspected myocardial infarction, and recent assessments have shown that in uncomplicated cases these tests give results which correlate satisfactorily with those of other procedures (Strandjord, Clayson, and Freier, 1962; Rosalki and Wilkinson, 1964; Preston, Received for publication 27 May 1965.
Batsakis, and Briere, 1964). Even if these methods are used, interpretation of raised serum enzyme activities may sometimes be difficult when myocardial infarction is suspected in the presence of disease of another organ, e.g., the liver. The present work was undertaken to determine whether certain selective inhibitors of the serum LDH have any diagnostic application in such cases. However, it was first necessary to investigate the effects of these compounds on the serum LDH of normal subjects and of patients with confirmed myocardial infarction or liver disease.

Sulphite was found by Wieland, Pfleiderer, and Ortanderl (1959) to inhibit preferentially the electrophoretically fast isoenzymes, $\mathrm{LDH}_{1}$ and $\mathrm{LDH}_{2}$, and subsequently oxalate was found to have a similar action (Plummer and Wilkinson, 1961, 1963; Emerson, Wilkinson, and Withycombe, 1964). More recently the slow isoenzymes, $\mathrm{LDH}_{4}$ and $\mathrm{LDH}_{5}$, have been shown to be inhibited by concentrations of urea which have little effect on $\mathrm{LDH}_{1}$ and $\mathrm{LDH}_{2}$ (Richterich and Burger, 1963; Plummer, Wilkinson, and Withycombe, 1963; Withycombe, Plummer, and Wilkinson, 1965). We, therefore, decided to use oxalate and urea as differential inhibitors in these studies.

The HBD/LDH ratio of the serum has been 
shown to be an index of the relative proportions of the electrophoretically fast and slow LDH isoenzymes, and high values have been observed in diseases associated with the presence of the fast isoenzymes $\mathrm{LDH}_{1}$ and $\mathrm{LDH}_{2}$, while low ratios occur in conditions in which the slow fractions, $\mathrm{LDH}_{4}$ and $\mathrm{LDH}_{5}$, are increased (Elliott, Jepson, and Wilkinson, 1962; Elliott and Wilkinson, 1963). As expected, the degrees of inhibition of the serum LDH with urea and oxalate were found to correlate with the HBD/ $\mathrm{LDH}$ ratio in uncomplicated cases, but we were especially interested in the application of inhibitor studies to patients in whom the effects of myocardial infarction were obscured by other disease.

The $\mathbf{L D H}_{1}$ molecule contains four identical subunits of the 'heart' or ' $\mathrm{H}$ ' type, while $\mathrm{LDH}_{5}$ consists of four identical sub-units of the 'muscle' or ' $M$ ' type; thus $\mathrm{LDH}_{1}$ and $\mathrm{LDH}_{5}$ might be described as $\mathrm{H}_{4}$ and $\mathrm{M}_{4}$ respectively. The isoenzymes of intermediate mobility are hybrids containing ' $\mathrm{H}$ ' and ' $M$ ' monomers and it has been suggested that $\mathrm{LDH}_{2}, \mathrm{LDH}_{3}$ and $\mathrm{LDH}_{4}$ might with advantage be designated $\mathrm{H}_{3} \mathrm{M}, \mathrm{H}_{2} \mathbf{M}_{2}$, and $\mathrm{HM}_{3}$ (Appella and Markert, 1961; Cahn, Kaplan, Levine, and Zwilling, 1962).

\section{METHODS}

DETERMINATION OF ENZYME ACTIVITIES Serum LDH and serum HBD activities were determined spectrophotometrically at $25^{\circ} \mathrm{C}$. by the methods of Wróblewski and LaDue (1955) and of Rosalki and Wilkinson (1960) respectively. Results are expressed as $\mu$ moles $\mathrm{NADH}_{2}$ oxidized per minute per litre of serum.
For inhibition studies $6 \mathrm{mM}$-potassium oxalate or $6 \mathrm{M}$-urea was made up in 0.067 M-Sørensen phosphate $\stackrel{9}{9}$ buffer at $p \mathrm{H} \mathrm{7.4}$. The solutions were stored at $4^{\circ} \mathrm{C}$. and $\overline{0}$ were freshly prepared at monthly intervals. Oxalate $\frac{}{0}$ solution $(0.1 \mathrm{ml}$.) or urea solution $(1.0 \mathrm{ml}$.) was incorpo- $\bar{\omega}$ rated into the reaction mixture of buffer, serum, and nucleotide about 30 minutes before the addition of the substrate. The final inhibitor concentrations were thus $\%$ $02 \mathrm{mM}$-oxalate and 2M-urea.

BLOOD SPECIMENS Blood was collected by venepuncture $\overrightarrow{\overrightarrow{\vec{H}}}$ from 16 healthy normal subjects, who served as controls, and from 19 patients who had suffered acute myocardial $ㄱ$ infarction one to four days previously and in whom the ? clinical diagnosis was confirmed by electrocardiography $\vec{\infty}$ and by serum aspartate amino-transferase and HBD $\dot{\sigma}$ determination. Blood samples from five patients with $\stackrel{\circ}{\circ}$ pernicious anaemia showing typical bone marrow changes $\omega$ and from 18 patients with liver diseases were also included in the survey. The liver disease group (diagnoses con- firmed by biochemical studies) comprised nine patients $Z$ with infective hepatitis, two with cirrhosis, two with massive hepatic metatases, two with massive liver necrosis following cardiac arrest or cardiac surgery, and one each of phosphorus poisoning, obstructive jaundice, and acute alcoholism.

\section{RESULTS}

NORMAL SERA The ranges of inhibition produced by $0.2 \mathrm{mM}$-oxalate and $2 \mathrm{M}$-urea are compared with the serum LDH and HBD activities in Figure 1.

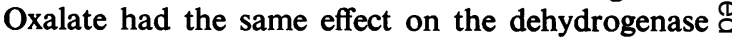
activity irrespective of whether LDH or HBD was $\overrightarrow{\vec{O}}$ determined. Urea, on the other hand, reduced the serum LDH activity to about $50 \%$ of the control

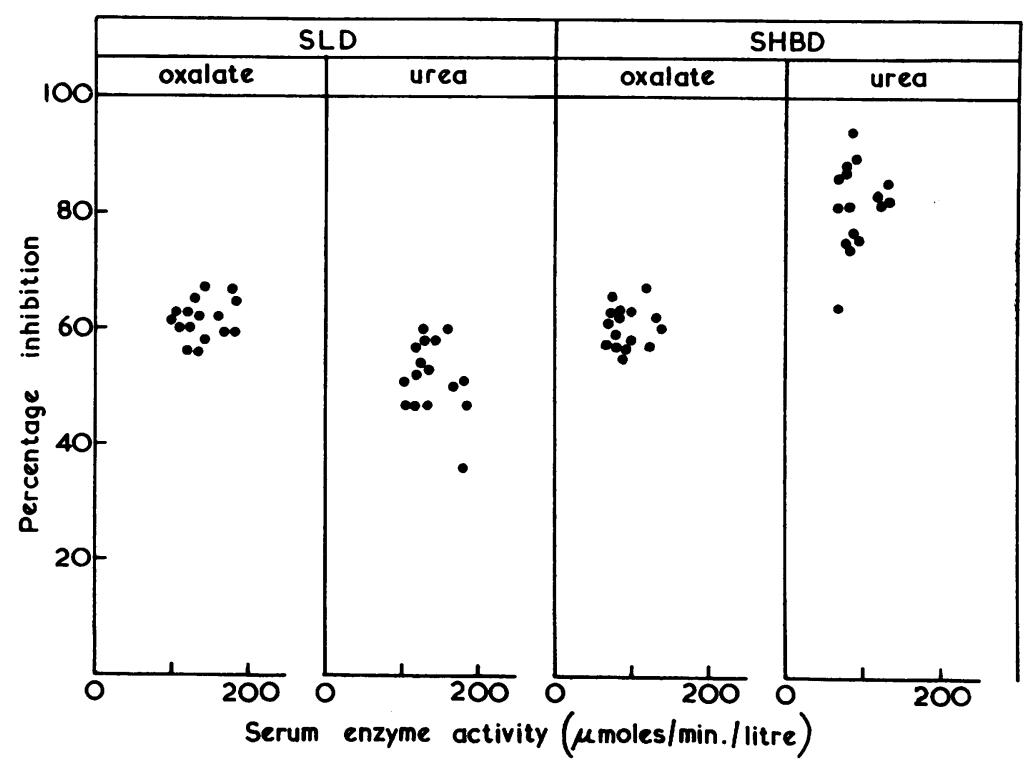

FIG. 1. The percentage inhibitions produced by $0.2 \mathrm{mM}$-oxide and $2 \mathrm{M}$-urea on the serum lactate dehydrogenase (SLD) and $\sigma$-hydroxybutyrate dehydrogenase (SHBD) activities of 16 normal subjects. 


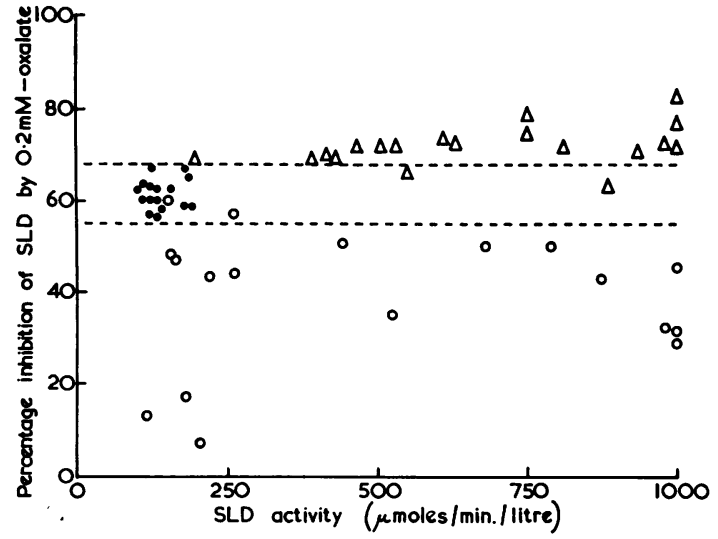

FIG. 2. The percentage inhibition produced by $0.2 \mathrm{mM}$ oxalate on the SLD activities of 19 patients with myocardial infarction $(\triangle), 18$ patients with liver diseases $(O)$, and 16 normal subjects $(\bigcirc)$. The broken lines represent the limits of the normal range for inhibition by oxalate.

value, but almost completely inhibited the serum HBD activity. This confirms the observation of Withycombe et al. (1965) who found that urea inhibited the lactate dehydrogenase activities of the crystalline ox-heart and rabbit-muscle enzymes and of human heart and human liver extracts to a much greater extent with 2-oxobutyrate as substrate than with pyruvate. Since the inhibition of the HBD activity of normal sera is almost complete with 2M-urea, it was considered that little purpose would be served by studying its effects on the HBD activity of pathological sera.

PATHOLOGICAL SERA The effects of oxalate on the serum LDH of 19 confirmed cases of myocardial infarction and of 18 of hepatocellular disease are compared with those on the LDH of normal sera in Figure 2. All except two of the sera from patients with heart disease exhibited inhibition greater than that found with normal sera: the two exceptions showed values for inhibition by oxalate within the normal range. In both of these cases, serum was collected for inhibitor studies on the third day, after the episode of chest pain, when the serum LDH and HBD activities were maximal and abnormally high HBD/LDH ratios were observed. Neither patient showed clinical evidence of heart failure.

Similarly the LDH of all except two samples from patients with liver diseases was less sensitive to oxalate inhibition and in this group also the exceptions showed values within the normal range. The first of these was from a girl of 21 with a history of mild jaundice extending over several days, but who was anicteric on admission (serum bilirubin, $0.9 \mathrm{mg}$./

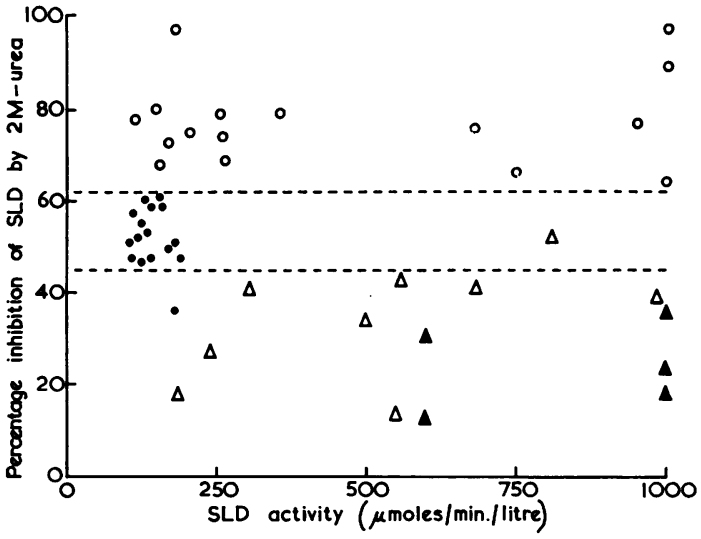

FIG. 3. The percentage inhibition produced by 2-M urea on the SLD activities of nine patients with myocardial infarction $(\triangle)$, five patients with megaloblastic anaemia $(\Delta), 16$ patients with liver diseases $(\bigcirc)$, and 16 normal subjects (O).

$100 \mathrm{ml}$.). The serum aspartate and alanine aminotransferases were raised to 43 and 70 i.u./l. respectively and the serum alkaline phosphatase was 22 King-Armstrong units; the serum $\mathrm{HBD} / \mathrm{LDH}$ ratio was subnormal, and the serum LDH was $80 \%$ inhibited by urea (see below). It was concluded that the patient was convalescing after infective hepatitis. The second exception was a man of 56 with rheumatoid arthritis and clinical jaundice, who had high serum aspartate and alanine aminotransferase levels (220 and 40 i.u./l. respectively), a subnormal serum $\mathrm{HBD} / \mathrm{LDH}$ ratio, and a serum $\mathrm{LDH} 70 \%$ inhibited by urea.

The effects observed with urea (Fig. 3) were the reverse of those found with oxalate, for the enzyme in the sera of patients with liver disease was inhibited to a much greater extent than that of normal sera, while with one exception the serum LDH of patients with myocardial infarction or megaloblastic anaemia was comparatively little affected by the presence of inhibitor. The anomalous patient in this group had suffered a typical episode of myocardial infarction: his elevated serum LDH was sensitive to oxalate ( $72 \%$ inhibition), but inhibition by urea of $50 \%$ fell in the normal range (Figure 3). There was some evidence, however, of coexisting liver damage, since the serum alanine aminotransferase was 45 i.u./l.

The percentage inhibitions obtained with both groups of pathological sera were shown by Student's $t$ test to be significantly different from those observed with the control sera. The mean percentage inhibitions and other statistical data are summarized in Table $\mathbf{I}$. 
TABLE I

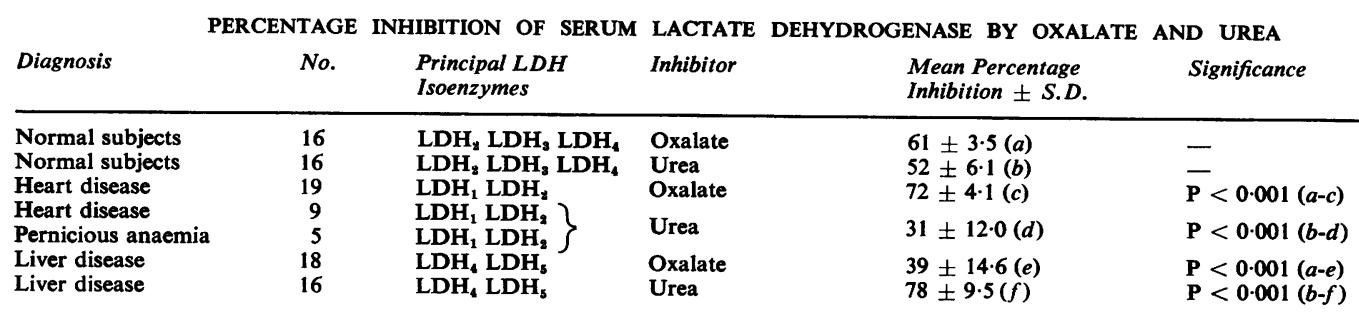

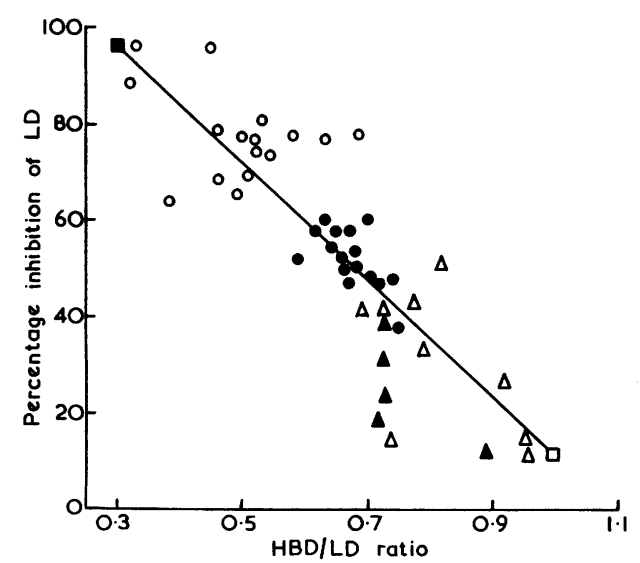

FIG. 4. The relation between the degree of inhibition of the $S L D$ by $2 M$-urea and the isoenzyme composition of the serum as represented by the $H B D / L D$ ratio. $\square$ and $\square$ represent the values observed with extracts of human heart and liver respectively, while the other symbols have the same significance as those in Figure 3.

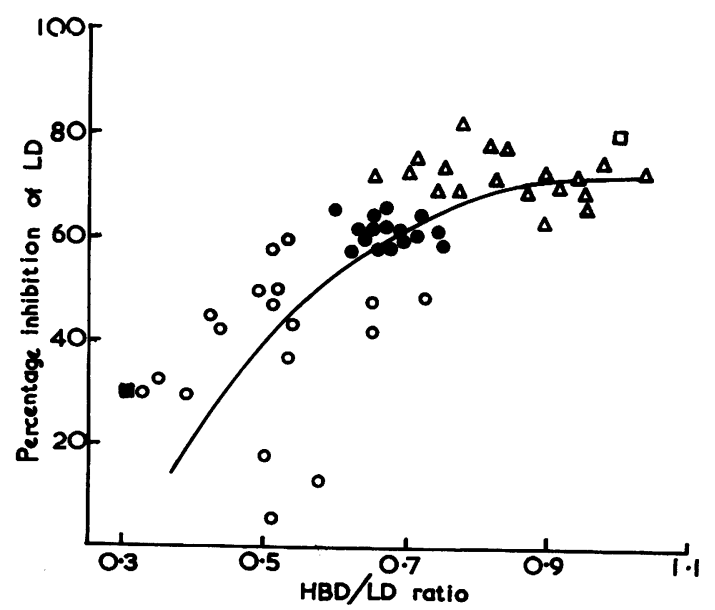

FIG. 5. The relation between the degree of inhibition of the $S L D$ by $0.2 \mathrm{mM}$-oxalate and the isoenzyme composition of the serum as represented by the $H B D / L D$ ratio. The symbols have the same significance as in Figure 4.
CORRELATION WITH OTHER INDICES OF ISOENZYME? COMPOSITION When the percentage inhibition was $\oplus$ plotted against the serum HBD/LDH ratio the points fell into three well-defined groups along a straight line in the case of urea (Fig. 4). Similar observations were made with oxalate but the relation was better represented by a curve sloping in the $z$ opposite direction to that obtained with urea (Fig. 5).

A correlation coefficient ( $r$ ) of $+\mathbf{0 . 8}$ was observed $\frac{3}{0}$ when the serum HBD/LDH ratio was plotted against the degree of inhibition with oxalate, $\vec{\bullet}$ expressed as $V / V_{i}$ where $V$ is the serum LDH activity of in the absence of the inhibitor and $V_{i}$ the activity in $\square$ its presence. When urea was used as inhibitor, a high degree of negative correlation was observed $(r=$ $-0 \cdot 7)$.

Since oxalate is a non-competitive inhibitor (Novoa, Winer, Glaid, and Schwert, 1959; Plummer $\stackrel{\circ}{\Rightarrow}$ and Wilkinson, 1963), we calculated the apparent inhibitor constant $\left(K_{i}\right)$ for each sample of serum and plotted the figures against SHBD/SLDH on semi-logarithmic paper. The three main groups of cases fell along a straight line with the cases of liver disease at one extremity and those with heart $\frac{0}{0}$ disease at the other. As the degree of inhibition diminishes, $K_{i}$ increases and the serum $\mathrm{HBD} / 8$ SLDH ratio falls.

APPLICATION OF INHIBITOR STUDIES TO DIAGNOSTIC PROBLEMS The following clinical examples illustrate conditions in which inhibition of the serum LDH by either oxalate or urea has aided diagnosis.

'Silent' myocardial infarction with minimal serum enzyme and electrocardiographic changes An 85-year-old male was admitted in congestive cardiac failure and an electrocardiogram suggested a recent small anterior- 0 septal infarction, though the patient had not experienced $\overparen{D}$ chest pain. Normal values for aspartate and alanine $\stackrel{?}{+}$ aminotransferase were observed but the LDH of 370 T i.u./1. and HBD of 250 i.u./l. were moderately raised with a normal HBD/LDH ratio: $73 \%$ inhibition by oxalate and $50 \%$ by urea suggested that most of the increased enzyme activity originated in cardiac muscle and supported the electrocardiographic evidence. 
Long-standing congestive cardiac failure with suspected recent mvocardial infarction A 48-year-old man with a long-standing history of cardiac failure was admitted with suspected myocardial infarction. An electrocardiogram showed evidence of left ventricular hypertrophy only, but his serum aspartate and alanine aminotransferases, LDH and HBD activites were increased. Inhibition of the serum LDH by oxalate, however, was only $49 \%$ as opposed to $73 \%$ by urea, suggesting that the patient had not suffered a recent infarction.

\section{DISCUSSION}

It is to be expected that serum from patients with conditions in which excessive amounts of $\mathrm{LDH}_{1}$ and $\mathrm{LDH}_{2}$ are released into the blood stream, such as myocardial infarction and megaloblastic anaemia, would be more sensitive to oxalate than would the sera of patients with liver diseases in which $\mathrm{LDH}_{4}$ and $\mathrm{LDH}_{5}$ usually predominate.

The slow isoenzymes, $\mathrm{LDH}_{4}$ and $\mathrm{LDH}_{5}$, are almost completely inhibited by $2 \mathrm{M}$-urea while $\mathrm{LDH}_{1}$ and $\mathrm{LDH}_{2}$ are but little affected (Richterich and Burger, 1963; Plummer et al., 1963; Withycombe et al., 1965), and urea would be expected to have the opposite effect.

It seems that, as a differential inhibitor of the serum LDH, urea may be of somewhat greater diagnostic value than oxalate, since it gave results which correlated with the diagnoses when applied to the sera which reacted anomalously with oxalate. Nevertheless, since they act in opposite senses, urea and oxalate are complementary to each other as inhibitors of the serum LDH. The results observed with both groups of pathological sera are highly significantly different $(P<0.001)$ from the control values when either of these inhibitors is used, and it therefore seems that determination of the percentage inhibition might well have applications in diagnosis. More than $68 \%$ inhibition by oxalate and less than $45 \%$ by urea is highly suggestive of cardiac damage, whereas if the urea inhibition is greater than $62 \%$ and that by oxalate less than $50 \%$, the liver is likely to be involved. Inhibitor studies have proved particularly useful when the serum HBD/LDH ratio is within the normal range and the diagnosis remains in doubt as, for example, in myocardial infarction complicated by congestive cardiac failure or in suspected liver disease when the dehydrogenase levels remain within the normal range.
As serum is usually diluted 1 in 30 for determinaticn of the LDH it is unlikely that the concentration of endogenous urea will ever be high enough to exert any inhibitory action, even in uraemia. Nevertheless, ultrafiltrates of uraemic sera have been shown to contain an inhibitor of rabbit muscle LDH (Morgan, Morgan, and Thomas, 1963), and in this laboratory we have consistently observed an increase in the serum LDH activity of uraemic patients after dialysis in an artificial kidney. The factor concerned however, has not so far been identified, but it does not appear to be urea.

We are most grateful to Miss Wendy A. Withycombe and Dr. D. T. Plummer for determining some of the enzyme activities reported in this paper and to Miss Margaret Cromwell-Thomas for skilled technical assistance, kindly financed by generous grants from C. F. Boehringer and Soehne GmbH, Mannheim, Germany.

\section{REFERENCES}

Appella, E., and Markert, C. L. (1961). Biochem. biophys. Res. Commun., 6, 171.

Cahn, R. D., Kaplan, N. O., Levine, L., and Zwilling, E. (1962). Science, 136, 962.

Elliott, B. A., and Wilkinson, J. H. (1961). Lancet, 1, 698.

-, (1963). Clin. Sci., 24, 343.

-, Jepson, E. M., and Wilkinson. J. H. (1962). Ibid., 23, 305.

Emerson, P. M., Wilkinson, J. H., and Withycombe, W. A. (1964). Nature (Lond.), 202, 1337.

Morgan, J. M., Morgan, R. E., and Thomas, G. E. (1963). Metabolism, 12, 1051.

Nisselbaum, J. S., and Bodansky, O. (1959). J. biol. Chem., 234, 3276. Novoa, W. B., Winer, A. D., Glaid, A. J., and Schwert, G. W. (1959). Ibid., 234, 1143.

Plagemann, P. G. W., Gregory, K. F., and Wróblewski, F. (1960). Ibid., 235, 2282.

Plummer, D. T., and Wilkinson, J. H., (1961). Biochem. J., 81, 38 P. $\longrightarrow$, , (1963). Ibid., 87, 423.

- _ , and Withycombe, W. A. (1963). Ibid., 89, $48 \mathrm{P}$.

Preston, J. A., Batsakis, J. G., and Briere, R. O. (1964). Amer. J. clin. Path., 41, 237.

Richterich, R., and Burger, A. (1963). Helv. physiol. pharmacol. Acta, $21,59$.

Rosalki, S. B., and Wilkinson, J. H. (1960). Nature (Lond.), 188, 1110. (1964). J. Amer. med. Ass., 189, 61.

Sayre, F. W., and Hill, B. R. (1957). Proc. Soc.exp. Biol. (N. Y.), 96, 695. Strandjord, P. E., Clayson, K. J., and Freier, E. F. (1962). J. Amer. med. Ass., 182, 1099.

Vesell, E. S., and Bearn, A. G. (1957). Proc. Soc. exp. Biol. (N.Y.), 94, 96.

Wieland, T., and Pfleiderer, G. (1957). Biochem. Z., 329, 112.

W., and Ortanderl, F. (1959). Ibid., 331, 103.

Withycombe, W. A., Plummer, D. T., and Wilkinson, J. H. (1965) Biochem. J., 94, 384.

Wróblewski, F., and LaDue, J. S. (1955). Proc. Soc. exp. Biol. (N.Y.), $90,210$. 